\title{
Fatigue Property of Al-5Zn-2Mg Aluminum Alloy Welding Joints Used in High-speed Trains
}

\author{
Ni Weiyuan", $\quad$ Yang Shanglei ${ }^{1,2}, \quad$ Jia Jin', $\quad$ Bai Jianying1, $\quad$ Lin Yangshenglan ${ }^{1}$ \\ ${ }^{1}$ College of Materials Engineering, Shanghai University of Engineering Science, Shanghai 201620, China; ${ }^{2}$ Shanghai Key Technology \\ Development Center of High Intelligent Laser Processing and Equipment Production, Shanghai University of Engineering Science, Shanghai \\ 201620, China
}

\begin{abstract}
The fatigue property of Al-5Zn-2Mg aluminum alloy Metal-Inert Gas (MIG) welding joints used in high-speed trains was studied by a fatigue machine. Scanning electron microscopy (SEM) was used to observe the fatigue fracture and the surface damage. The results show that uniaxial ratcheting behavior occurs in the welding zone (WZ) when the stress is higher than $0.5 \sigma_{\mathrm{b}}$; there are obvious plastic deformations in the WZ and a lot of slip bands on the surface, which reduce the fatigue life of the sample. The uniaxial ratcheting behavior mainly appears in the first cycle and the final failure stage of the fatigue process. When the stress is lower than $0.5 \sigma_{\mathrm{b}}$, the fatigue samples crack in the heat affected zone (HAZ). The fatigue fracture of the WZ and the fusion zone (FZ) is typical ductile fracture pattern while that of the HAZ and the base metal (BM) is quasi-cleavage fracture. The fatigue life of the $\mathrm{BM}$ is much longer than that of the HAZ.
\end{abstract}

Key words: $\mathrm{Al}-5 \mathrm{Zn}-2 \mathrm{Mg}$ aluminum alloy; ratcheting strain; slip band; fatigue fracture

With the rapid development of high speed trains, it makes a higher request on vehicle lightweight and low energy consumption as well as security and reliability. The stiffness, strength, processing performance, stress corrosion resistance and welding property of $\mathrm{Al}-\mathrm{Zn}-\mathrm{Mg}$ alloy are very well ${ }^{[1]}$. However, after the action of long-term stress, the welding material may cause fatigue damage, making a higher requirement on the fatigue performance of welding joints.

Precipitated strengthening phase of $\mathrm{Al}-\mathrm{Zn}-\mathrm{Mg}$ alloy separate out in the sequence of G.P. zone, $\eta^{\prime}$ phase and $\eta$ phase ${ }^{[2,3]}$. In recent years, many researches have been conducted on $\mathrm{Al}-\mathrm{Zn}-\mathrm{Mg}$ alloy. Coarse particles in ground boundary such as $\mathrm{Al}_{7} \mathrm{Cu}_{2} \mathrm{Fe}, \mathrm{Al}_{3} \mathrm{Fe}, \mathrm{Mg}_{2} \mathrm{Si}$ or impurity element enrichment such as $\mathrm{Fe}$ and $\mathrm{Si}$ could affect the fatigue property of $\mathrm{Al}-\mathrm{Zn}-\mathrm{Mg}-\mathrm{Cu}$ alloy and it could cause fatigue damage ${ }^{[4,5]}$. Many welding processes could be used in the aluminum alloy. The most widely used welding process in high speed trains is still MIG (Metal-Inert Gas) ${ }^{[6-8]}$. Until now there is lack of study on the fatigue property of $\mathrm{Al}-\mathrm{Zn}-\mathrm{Mg}$ alloy welding joints.
This paper is mainly about uniaxial fatigue property of $\mathrm{Al}-5 \mathrm{Zn}-2 \mathrm{Mg}$ aluminum alloy welding joints. It is a previous work to make the high speed trains develop in the direction of a safer, more reliable and durable way.

\section{Experiment}

The material used in the present study was $\mathrm{Al}-5 \mathrm{Zn}-2 \mathrm{Mg}$ aluminum alloy which was welded by the process of MIG filler wire welding with ER5356welding electrode. Fatigue tests on the welding joints, the heat affected zone (HAZ) and the base metal (BM) were performed by an IBTC-2000 fatigue machine. The tension-tension cyclic loading at a stress ratio of $R=0$ was applied at a frequency of $1 \mathrm{~Hz}$ and sinusoidal waveform. The dimension of the fatigue test specimen is shown in Fig.1. S-3400N SEM was used to research fatigue fracture morphology and surface damage. And the microhardness was tested by a HXD-1000 microhardness tester.

Received date: November 14, 2015

Foundation item: National Natural Science Foundation of China (51075256)

Corresponding author: Ni Weiyuan, Candidate for Master, College of Materials Engineering, Shanghai University of Engineering Science, Shanghai 201620, P. R. China, Tel/Fax: 0086-20-67791198, E-mail: nwy1989@126.com 


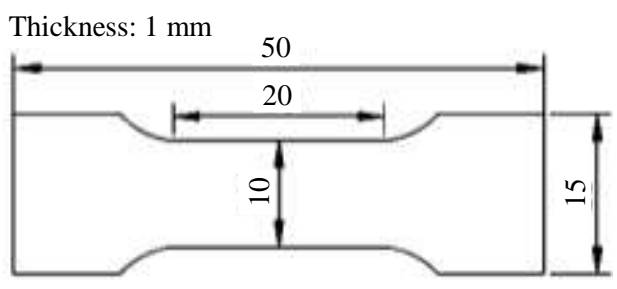

Fig.1 Fatigue test specimen (unit: $\mathrm{mm}$ )

\section{Results and Discussion}

\subsection{Fatigue life and the fracture sites}

The results of fatigue tests are shown in Table 1. The percentage elongation of sample $\mathrm{A}, \mathrm{B}$ and $\mathrm{C}$ after fracture shows an obvious plastic deformation in the welding joints samples. The plastic deformation increases with the increasing stress. The comparison of A5, B6, and C7 shows that, when the stress is the same, the fatigue life of the welding joints sample is the shortest. The percentage elongation after fracture of the welding joint sample is the largest. However, that of the $\mathrm{HAZ}$ and the BM sample is only $0.5 \%$. It indicates that the plastic deformation happens in welding joints mainly in the $\mathrm{WZ}$; in that case, the failure in welding joint sample is attributed to the large amounts of plastic deformation in the WZ. It also indirectly indicate that the tensile strength of the WZ is relatively low. From the comparison of sample B and C, the fatigue life of the HAZ sample is far below that of the BM. It states that the fatigue property of the HAZ declines owing to the welding thermal cycle.

The tensile strength $\left(\sigma_{\mathrm{b}}\right)$ of the $\mathrm{Al}-5 \mathrm{Zn}-2 \mathrm{Mg}$ aluminum alloy MIG welding joints is $280 \mathrm{MPa}$ and the tensile fracture is located in WZ. When the fatigue stress is higher than $0.5 \sigma_{\mathrm{b}}$, the welding joint samples crack in the FZ.

The microhardness distribution is shown in Fig.2. The microhardness $\mathrm{HV}$ gradient in the FZ is large, rising rapidly from $800 \mathrm{MPa}$ to $1244 \mathrm{MPa}$ when transited from the WZ to the HAZ. And the plastic deformation in the HAZ and the WZ is markedly different, which leads to the stress concentration in the FZ and makes the FZ a weak region of the welding

Table 1 Results of fatigue tests of Al-5Zn-2Mg aluminum alloy

\begin{tabular}{cccccc}
\hline $\begin{array}{c}\text { Specimen } \\
\text { ID }\end{array}$ & $\begin{array}{c}\sigma_{\max } / \\
\text { MPa }\end{array}$ & $\begin{array}{c}\sigma_{\min } / \\
\text { MPa }\end{array}$ & $\begin{array}{c}\text { Cycles } \\
\text { number }\end{array}$ & Final state & $\begin{array}{c}\text { Elongation/ } \\
\%\end{array}$ \\
\hline A1 & 120 & 0 & 96853 & No failure & - \\
A2 & 150 & 0 & 28891 & Failure in HAZ & 4.3 \\
A3 & 180 & 0 & 11214 & Failure in FZ & 4.8 \\
A4 & 210 & 0 & 9075 & Failure in FZ & 5.3 \\
A5 & 240 & 0 & 4688 & Failure in FZ & 8.8 \\
B6 & 240 & 0 & 29436 & Failure & 0.5 \\
C7 & 240 & 0 & 198713 & Failure & 0.5 \\
\hline
\end{tabular}

Note: A stands for the samples of welding joints, B stands for the sample of HAZ, and C stands for the sample of BM

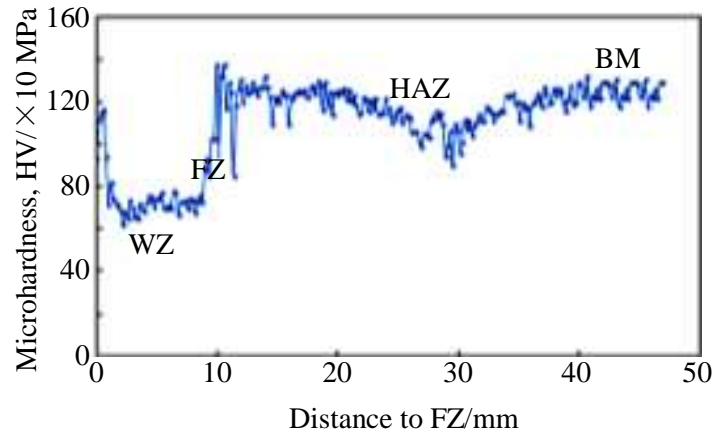

Fig.2 Microhardness (HV) of Al-5Zn-2Mg aluminum alloy welding joints

joints. So the welding joint samples are most likely to break in the $\mathrm{FZ}$ at the fatigue stress higher than $0.5 \sigma_{\mathrm{b}}$.

When the fatigue stress is lower than $0.5 \sigma_{\mathrm{b}}$, the plastic deformation as well as the stress concentration in the WZ significantly decrease. In that case, the FZ is no longer the weakest region of welding joints. However, the HAZ full of compound particles which is brittle and hard, could initiate cracks more easily and lead to final fracture in the HAZ (sample A2) under the action of a long period of low fatigue stress. So the WZ, FZ, and HAZ showing different stress sensitivity determine the different fracture positions of welding joints.

\subsection{Ratcheting behavior}

Fig. 3 shows the ratcheting strain of sample A2, A4, and A5 changing along with the number of cycles. Ratcheting effect is the result of inelastic deformation accumulation during the cycles in the process of asymmetric stress control. Ratcheting strain can make the material produce great plastic deformation and result in the decrease of material fatigue life. The uniaxial ratcheting strain is defined as follows:

$$
\varepsilon_{\mathrm{r}}=\left(\varepsilon_{\max }+\varepsilon_{\min }\right) / 2
$$

where, $\varepsilon_{\max }$ and $\varepsilon_{\min }$ are the maximum and the minimum ratcheting strain in each cycle, respectively, and $N$ is the number of cycles. The strain evolution could be divided into three stages: transient, steady state and tertiary ${ }^{[9]}$. At the transient stage, there is an initial sharp increase in the ratcheting strain but a decrease in the ratcheting strain rate because of cyclic strain hardening. And the ratcheting strain accumulates to a large value in a short period of time. The ratcheting strain accumulating at the transient stage decreases with decreasing the maximum stress. At the steady state stage, the ratcheting strain rate remains stable (approximate 0) without any change. At the tertiary stage, the material deformation resistance declines, and the ratcheting strain increases sharply, leading to great plastic deformation and ultimate fracture of the samples ${ }^{[10]}$. And the ratcheting strain accumulating at the tertiary stage increases with the decreasing maximum stress. But to the whole process, the ratcheting strain is larger when the stress is higher. 


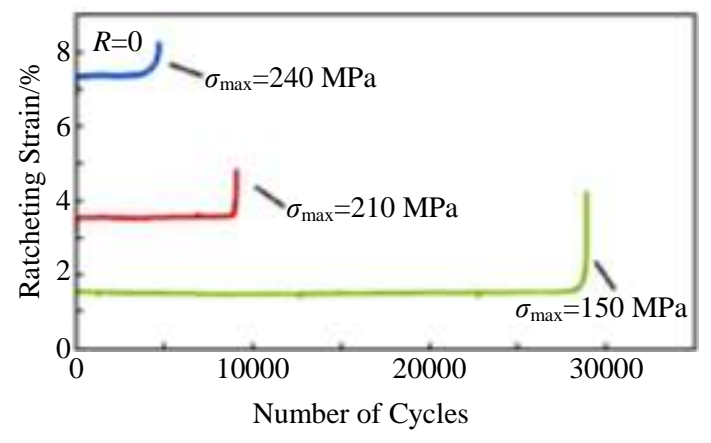

Fig.3 Ratcheting strain versus number of cycles

Uniaxial hysteretic stress-strain curves of welding joints in different stress at the first cycle are shown in Fig.4. The hysteretic stress-strain curves are unclosed in the first cycle owing to the large plastic deformation. The plastic deformation in the first cycle increases with the increasing stress. From the observation in the process of experiment, the WZ surface turns tough after the first cycle. When the stress increases, the $\mathrm{WZ}$ surface becomes rougher.

Fig.5 shows stress-strain curves of welding joints in different stress from the 2 nd cycle to the last cycle. From the comparison of Fig.5a, 5b, 5c, it can be concluded that the strain rate of all the samples slows down rapidly after the first cycle and the stain of the second cycle almost overlaps the latter half of the first cycle because of the cyclic strain hardening generated by the large number of plastic deformation in the first cycle. The number of cycles needed to achieve stability increase with increasing stress. At the stable stage, the strain remains unchanged until the specimen reaches to the failure stage. The plastic deformation at the failure stage decreases with increasing of stress. For example, when the maximum stress is 240,210 and $150 \mathrm{MPa}$, plastic deformation occurs in the failure stage is 500, 50, 2 cycle, respectively.

\subsection{Slip band on WZ surface}

Fig.6 shows SEM morphologies of slip band on the WZ surface. In Fig.6a, there are two slip systems of different

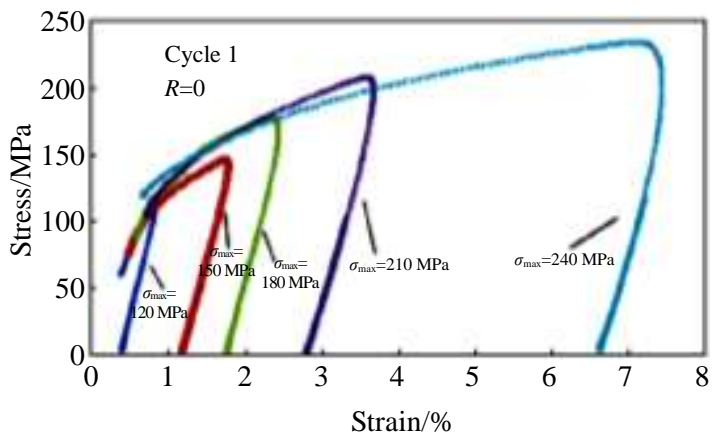

Fig.4 Ratcheting behavior of uniaxial stress-strain response at the first cycle
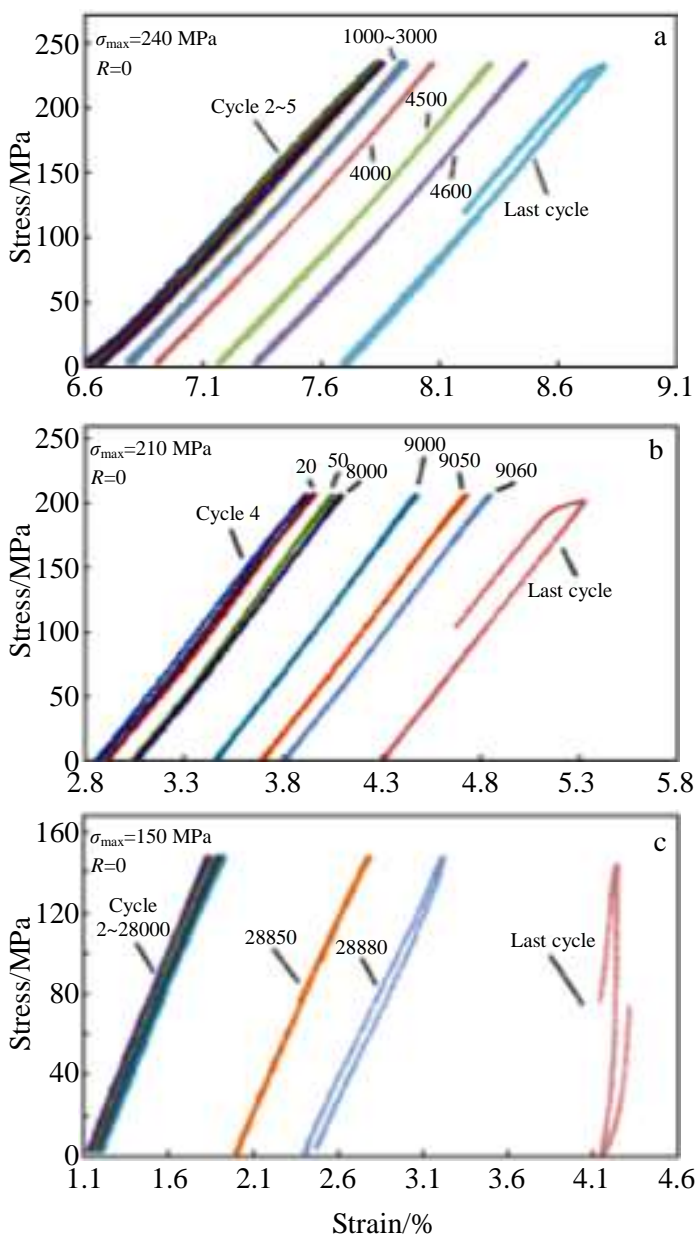

Fig.5 Ratcheting behavior of uniaxial stress-strain response at the maximum stresses of $240 \mathrm{MPa}$ (a), $210 \mathrm{MPa}$ (b), $150 \mathrm{MPa}$ (c)

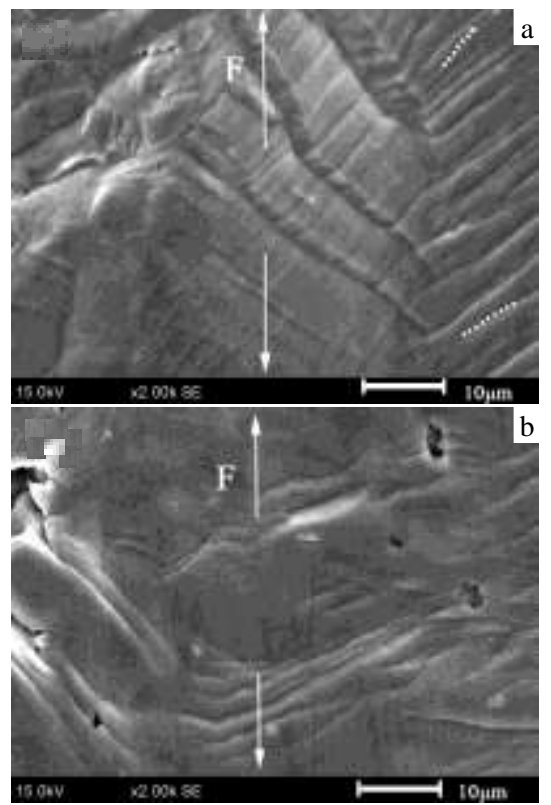

Fig.6 SEM morphologies of slip band on WZ surface: (a) feature of slip band and (b) crack at slip band 
sliding direction slips along the same grain boundary. The angle between sliding direction and tensile stress direction is about $45^{\circ}$ which is the optimum angle to achieve shear stress needed to a crystal slip. The dotted lines marked along the direction of slip plane in the crystal of right side show that slip plane and slip direction exhibit a bottom-up deflection and finally coincide with the slip direction of the left crystal. Under the action of tensile stress, the crystals slip towards the direction of about $45^{\circ}$, leading to a certain amount of lateral displacements. But the fixture of the tensile machine can't do transverse movement, so in order to keep tensile axis direction unchanged, the crystal orientation must be accordingly rotated and it leads to the change of the slip plane direction. In the left crystal binary slip exists which has two entirely different sliding directions in a crystal. The slip begins first in the most advantageous orientation. Due to the rotation of crystal orientation, the shear stress of another slip plane has increased to the critical shear stress to begin slip. So the two slip planes both slip in the same crystal. Fig.6b shows cracks at slip band. This states that excessive amounts of plastic deformation could lead to micro-cracks initiation and reduce fatigue life.

\section{Fractograph}

Fig.7 represents the fatigue fracture of the WZ, FZ, HAZ and BM. In which letter a, b, c marked in the figure stand for the fatigue initiation site, fatigue crack propagation site and final fracture site, respectively. The fractures of four different zones show that fatigue initiation site are generally located on or near the surface of samples.

As shown in Fig.7a, the WZ fracture has three obvious crack initiation sites, all of which is on or near the surface of the sample. Fatigue crack propagation range of the middle one is very small, only about $80 \mu \mathrm{m}$. The fatigue initiation site of the right one starts from the slip band on the surface of the $\mathrm{WZ}$. The fatigue initiation site in the $\mathrm{WZ}$ is more various than in other regions. These initiations propagate inside and finally gather together, leading to the final fracture of the sample.

As shown in Fig.7b, fatigue initiation of the FZ is caused by two blowholes. The size of the hole is big $(85 \mu \mathrm{m} \times 72 \mu \mathrm{m})$ that has reached the critical size of the crack nucleation (generally defined as $0.05 \sim 0.1 \mathrm{~mm})$. In that case, fatigue crack nucleation could easily happen in the hole edge. Final fracture zone of the WZ and the FZ is characterized by dimpled rupture. It indicates that toughness of the $\mathrm{WZ}$ and the $\mathrm{FZ}$ is well.

Fig.7c and $7 d$ show that both the fatigue cracks of the HAZ and the BM initiate from the surface, accurately in the corner where the stress is the most concentrated. Fatigue crack propagation area of the $\mathrm{HAZ}$ is the smallest of the other three (the FZ, HAZ, BM) and that of the BM is more than half of the whole fracture. This declares that the fatigue crack propagation life of the HAZ is the shortest and the resistance to fatigue crack propagation of the HAZ is poor. The boundary between the fatigue crack propagation site and the final fracture site in the HAZ and the BM is clearly visible, where there is a large tear ridge. Few dimples and a lot of cleavage facet and tear ridges exist in the final fracture site of the HAZ and the BM, demonstrating that the fracture of the HAZ and the $\mathrm{BM}$ is brittle and the toughness of the HAZ and the BM is not as good as that of the WZ and the FZ. In addition, tear ridges in the fracture of the HAZ are much more and the cleavage facet is bigger than that of the BM. It also explains that the toughness of the HAZ and its resistance to fatigue crack propagation are not as good as those of the BM.

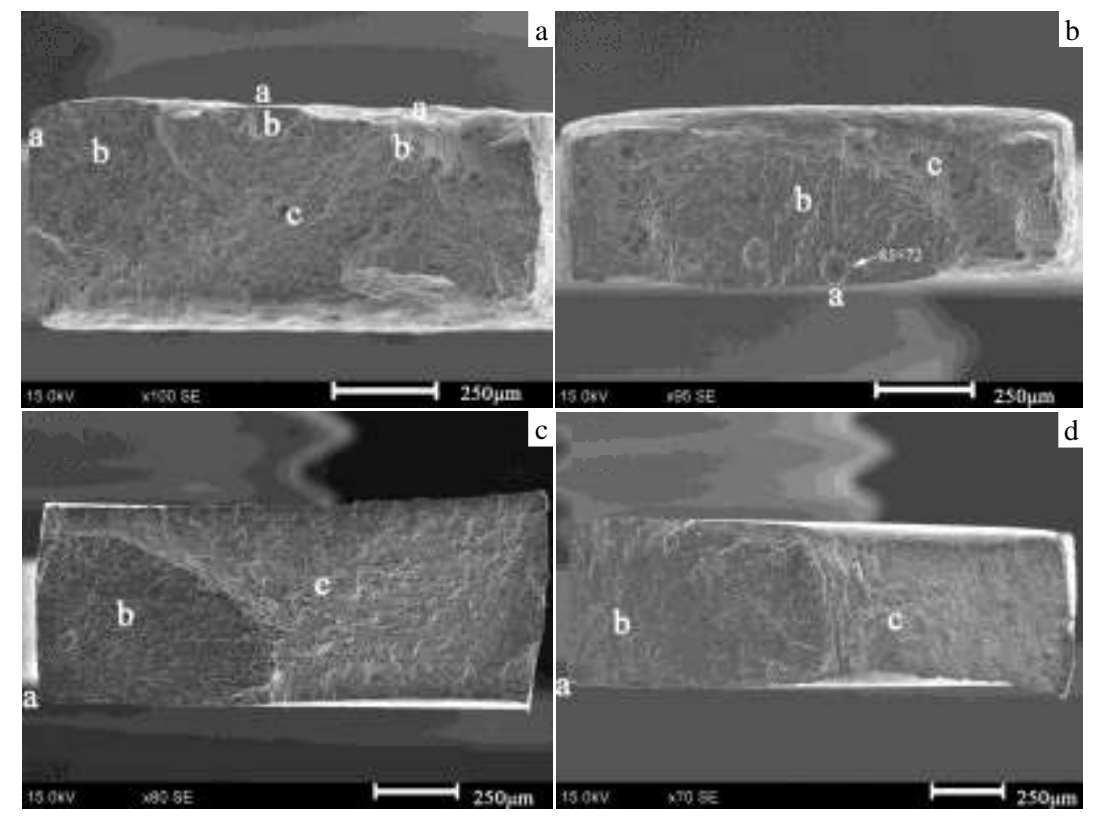

Fig.7 SEM fracture morphologies of WZ (a), FZ (b), HAZ (c), and BM (d) 


\section{Conclusions}

1) For the sample of $\mathrm{Al}-5 \mathrm{Zn}-2 \mathrm{Mg}$ welding joints, it fractures in the $\mathrm{FZ}$ when the stress is higher than $0.5 \sigma_{\mathrm{b}}$, or it fractures in the HAZ when the stress is lower than $0.5 \sigma_{\mathrm{b}}$. But to the sample of the HAZ and the BM, the fatigue life of the $\mathrm{HAZ}$ is much shorter than that of the BM at the same stress.

2) Ratcheting strain in the WZ is divided into three stages: transient, steady state and tertiary. At the transient stage plastic deformation mainly focuses on the first cycle.

3) Slip band in the WZ is complicated. There exist repeated slip, binary slip and crystal rotation and slip plane rotation. The slip band could initiate micro-cracks and decrease the fatigue life.

\section{References}

1 Iqbal M, Shaikht Ma, Ahmad M et al. Journal of Materials Processing Technology[J], 2000, 16: 319

2 Sun Y P, Yan $\mathrm{H} \mathrm{G}$, Chen Z H. Metal Science and Heat
Treatment $[\mathrm{J}], 2009$, 51: 394

3 Sharma M M, Ziemian C W, Eden T J. Journal of Materials Engineering and Performance[J], 2010, 19: 1344

4 She Huan, Shu Da, Chu Wei et al. Metallurgical and Materials Transactions A[J], 2013, 44: 3504

5 Jiang Feng, Wen Kang, Jiang Long et al. Transaction of Nonferrous Metals Society of China[J], 2009, 19: 1031

6 Feng A H, Chen D L, Ma Z Y. Metallurgical and Materials Transactions A: Physical Metallurgy and Materials Science[J], 2010, 41: 2626

7 He Z B, Peng Y Y, Yin Z M et al. Transactions Nonferrous Metals Society of China[J], 2011, 21: 1685

8 Stefano M, Chiars S. Journal of Materials Processing Technology[J], 2008, 197: 237

$9 \mathrm{Yu} \mathrm{D}$ J, Chen G, Yu W W et al. International Journal of Plasticity[J], 2012, 28: 88

10 Lin Y C, Liu Z H, Chen X M et al. Compound Materials Science[J], 2013, 73: 128

\title{
高速列车用高强 A7N01 铝合金焊接接头的疲劳性能
}

\author{
倪维源 ${ }^{1}$, 杨尚磊 ${ }^{1,2}$, 贾 进 ${ }^{1}$, 白健颙 ${ }^{1}$, 林杨胜蓝 ${ }^{1}$
}

(1. 上海工程技术大学材料工程学院, 上海 201620)

(2. 上海工程技术大学高强激光智能加工装备关键技术产学研开发中心，上海 201620)

\begin{abstract}
摘 要: 用 IBTC-2000 型疲劳机对高速列车用 A7N01 (Al-5Zn-2Mg) 铝合金 MIG 焊焊接接头、热影响区和母材试样进行疲劳试验, 用 扫描电子显微镜(SEM)观察疲劳断口以及疲劳表面损伤形貌。结果表明, 应力高于 $0.5 \sigma_{\mathrm{b}}$ 时, 焊缝部位会产生棘轮应变, 发生了明显的 塑性变形, 表面有明显滑移带, 会降低焊接接头试样的疲劳寿命。焊缝部位发生的塑性变形主要集中发生在疲劳过程的第 1 循环和最后 的失效阶段。当应力低于 $0.5 \sigma_{\mathrm{b}}$ 时, 断口位于热影响区。焊缝和熔合区断口为延性断口, 热影响区和母材试样断口为准解理断口。母材 的疲劳寿命远远高于热影响区试样的疲劳寿命。
\end{abstract}

关键词: A7N01 铝合金; 棘轮应变; 滑移带; 疲劳性能

作者简介: 倪维源, 女, 1989 年生, 硕士生, 上海工程技术大学材料工程学院, 上海 201620, E-mail: nwy1989@126.com 